\title{
Design of Compact BranchlineBalun
}

\author{
Indhumathi $\mathrm{J}^{\mathrm{a}, 1}$, and Maheswari $\mathrm{S}^{\mathrm{b}}$ \\ a PG Scholar, Deptof ECE,Panimalar Engineering College, Chennai \\ ${ }^{\mathrm{b}}$ Professor, Dept of ECE,Panimalar Engineering College, Chennai
}

\begin{abstract}
This paper present the compact branch line balun to operate at the frequency range of $2.4 \mathrm{GHz}$. The compact branchlinebalun is designed using the substrate material with the dielectric constant of $\mathrm{FR}_{4}$ material. The proposed balun is designed using different transmission lines. Thus the balun should achieves $-3 \mathrm{~dB}$ power division and $180^{\circ}$ phase differences between the outputs. The main objective of this design focuses on size reduction. To reduce the size, A balun is realized using the equivalent T-shape structure. After the reduction techniques the implemented size of the balun is $29.41 \times 44.32 \mathrm{~mm}^{2}$ achieves $35 \%$ of size reduction. Thus the measured $S_{11}$ are $-23 \mathrm{~dB}$ and the $\mathrm{S}_{21}, \mathrm{~S}_{31}$ remains $-3 \mathrm{~dB}$ and provide $179^{\circ}$ phase difference between the outputs at the frequency of $2.4 \mathrm{GHz}$.
\end{abstract}

Keywords. Branchlinebalun, Transmission lines, Size reduction, T-shaped structure.

\section{Introduction}

A balun is a device used to balance the unbalanced one. A branch line balun is an important features for designing microwave circuits. The baluns are used in various applications such as mixers, amplifiers, frequency multipliers, couplers and so-on. They are widely used in antennas to balance the circuit design. The microstripbalun are also used in many microwave applications. There are many types of baluns-the designs structures are generally depending on the bandwidth, operating frequency, physical architecture of the network. The branchlinebalun provide equal amplitude and phase difference between the circuit design. The branchlinebalun increases the complexity and also achieves better return loss and isolation loss. The branchlinebalun provide wider bandwidth.

This paper focus on size reduction of the balun with $180^{\circ}$ of phase differences. The proposed balun is designed using different transmission lines composed of two $\lambda / 4$ transmission lines on horizontal branches and two $\lambda / 2$ transmission lines on vertical branches. The characteristic impedances of the balun are $\sqrt{2} Z_{0}=70.7 \Omega$. When the transmission lengths are reduced, characteristics impedances are increased. The size reduction depends on higher impedance transmission lines. By decreasing the length of transmission lines, the entire size of the structure can became compact. In this paper, the reduced size of the balun is presented.

\footnotetext{
${ }^{1}$ Indhumathi J,PG scholar, Department of ECE, Panimalar Engineering College, Chennai;

E-mail: jaiindhu96@gmail.com
} 


\section{Related works}

M. Y. Algumaeiet. al [1] has proposed single balanced mixers for ultra wide band applications. This balun operates at the frequency of $100 \mathrm{MHz}$. Thus the design obtain the phase difference of $180^{\circ}$ with the conversion loss of $19 \mathrm{~dB}$ from $3.1-10 \mathrm{GHz}$. Mi Zhou et.al [2] has designed a novel planar branch line balun with the symmetrical network with the transparent port impedance. The balun achieves $180^{\circ}$ phase difference with the better return loss of $-30 \mathrm{~dB}$ operates at the frequency of $1 \mathrm{GHz}$. Li Chang et.al [3] has demonstrated dual band branch line balun at two different frequencies of $1.5 \&$ $2.5 \mathrm{GHz}$. The simulated return loss are $16.5 \mathrm{~dB}$ and also attains $180^{\circ}$ phase difference between the output ports. Chih-Jung Chen et.al [4] has implemented derivation of Tshaped structures for quarter wave transmission lines at the frequency of $2.4 \mathrm{GHz}$ and achieves $180^{\circ}$ phase difference. He-XiuXuet. al [5] has proposed a compact balun with enhanced bandwidth with the operating frequency of $1.5 \mathrm{GHz}$ and attains a return loss of $10 \mathrm{~dB}$ and good amplitude and phase imbalance.Myun-Joo Park [6] has used stubs for reducing the branch length in order to reduce the area of the balun at the centre frequency of $1 \mathrm{GHz}$. Hee-Ran Ahn[7-8] has designed ministurizedbalun at the centre frequency of $900 \mathrm{MHz}$ with short coupled lines to obtain $180^{\circ}$ phase difference. MingGuangChen[9-10] has implemented miniatuirzedbalun design with $2.4 \mathrm{GHz}$ for dual band transmission line with $60 \%$ size reduction.

\section{Structure Description and Analysis}

A balun is a three port network with port 1 as a input and port 2 and port 3 as a outputs. Thus each port act as a transmitter and receiver. The structured branch line balun (Fig.1) where $Z_{A}$ and $Z_{B}$ represents the characteristic impedance $\sqrt{2} Z_{0}=70.7 \Omega$ whereas the wavelength of $Z_{A}$ and $Z_{B}$ represent the quarter wavelength transmission line $(\lambda / 4)$ and the half wavelength transmission line $(\lambda / 2)$. The length and width of both the transmission lines are calcultaed and are mentioned in Table1. The input signal should split equally between the output ports. Thus the balunshould provide $-3 \mathrm{~dB}$ power division and $180^{\circ}$ phase difference between the two output ports.

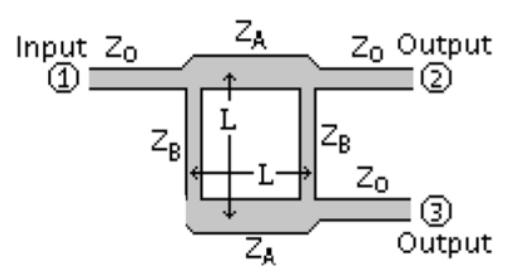

Figure 1. Structure of Branch line Balun
Table 1. Dimensions of Balun

\begin{tabular}{|c|c|c|}
\hline Parameter & Length(mm) & Width(mm) \\
\hline$Z_{\mathrm{O}}$ & 17.2 & 3.058 \\
\hline $\mathrm{Z}_{\mathrm{A}}$ & $17.54(\lambda / 4)$ & 1.623 \\
\hline $\mathrm{Z}_{\mathrm{B}}$ & $35.08(\lambda / 2)$ & 1.623 \\
\hline
\end{tabular}



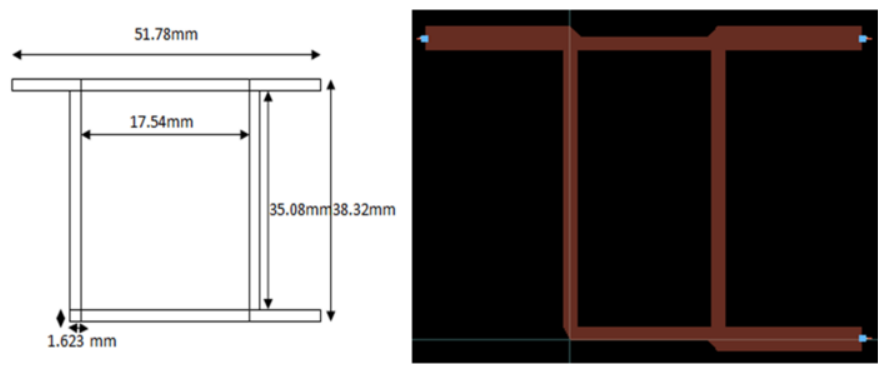

Figure 2. Layout of the balun designed at $2.4 \mathrm{GHz}$ with its dimensions

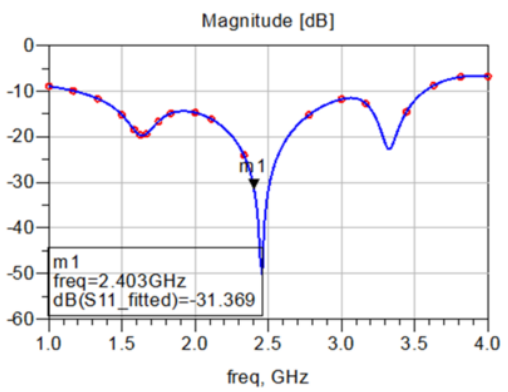

Figure 3. Simulated result of $S_{11}$
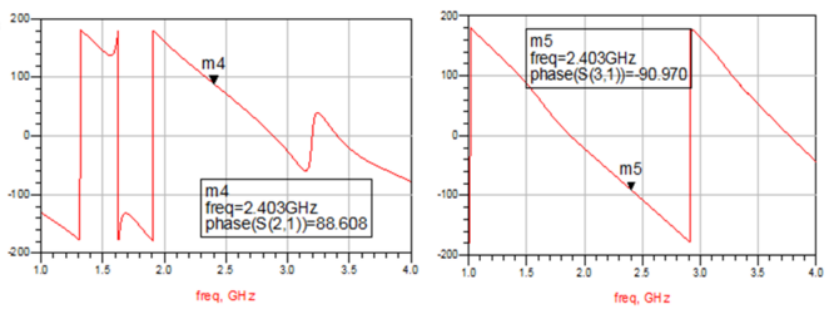

Figure 4. Phase of $S_{21}, S_{31}$.

The balun is optimized and simulated using ADS software with dielectric constant $\mathrm{\varepsilon r}=$ $4.4\left(\mathrm{FR}_{4}\right.$ substrate $)$ and at the thickness of $\mathrm{h}$ is $1.6 \mathrm{~mm}$. The scattering parameter of this balun is simulated by the Electromagnetic (EM) simulation tool over the frequency of 2.4GHz. Thus the simulated $\mathrm{S}_{21}, \mathrm{~S}_{31}$ are -3.453 and $-3.340 \mathrm{~dB}$. The obtained $\mathrm{S}_{11}$ are -31 $\mathrm{dB}$ over the same frequency. The implemented szie of the branch line balun are $38.32 \mathrm{x}$ $51.78 \mathrm{~mm}^{2}$. Therefore the balun obtains $178^{0}$ phase differences between the output $\mathrm{S}_{21}, \mathrm{~S}_{31}$ over $2.4 \mathrm{GHz}$. The main focus of the balun focus on size reduction technique.

\section{Size Reduction Technique}

The size reduction technique or miniaturization of the balun can be implemented using various design procedures such as T-shaped structure, stepped impedance of the balun, by adding stubs along its branches, by using different transmission lines. In this proposed design size reduction is done by the equivalent $\mathrm{T}$-shaped structure. The Proposedbalun of $\lambda / 4, \lambda / 2$ transmission lines are replaced by the equivalent $\mathrm{T}$-shaped structure is shown in Fig 5.a. The compact T-shaped structure can be obtained from the 
following cases, Where

$\mathrm{M}=\mathrm{Z}_{1} / \mathrm{Z}_{0}(\mathbf{1})$

$\mathrm{K}=\mathrm{Z}_{1} / \mathrm{Z}_{2}(\mathbf{2})$

Thus the total electrical length $\Theta_{\mathrm{T}}=2 \Theta_{1}+\Theta_{2}$. In order to avoid the overlapping between the stubs length $\Theta_{2}$ should be lesser than $\Theta_{1}\left(\Theta_{1}<\Theta_{2}\right)$ and the stub length of $\Theta_{2}$ should be plotted against $M$ or $\Theta_{1}$ can be plotted for the different values of $\mathrm{K}$. The total electrical length $\Theta_{\mathrm{T}}$ decreases when $\mathrm{K}$ increases, where the $\Theta_{\mathrm{T}}$ depends only on M.

Therefore ., $\quad \tan \Theta_{1}=1 / \mathrm{M} \quad$ (3)

$\tan \Theta_{2}=1 / \mathrm{K}\left(\cot \Theta_{1}-\tan \Theta_{1}\right)$

First select the parameter for the T-shaped structure whose characteristics impedance $Z_{0}=70.7 \Omega$, where, $Z_{1}=M . Z_{0}=155.54 \Omega$ for $M=2.2$ of $\Theta_{1}=24.5^{0}$ such that $Z_{2}=Z_{1} / K=38.85 \Omega$ for $K=4$ of $\Theta_{2}=23.5^{0}$.Thus the total electrical length $\Theta_{T}=73^{0}$. Thus the calculated length and width for $Z_{1}$ and $Z_{2}$ are shown in table.2.

Table 2. Dimensions of conventional Balun
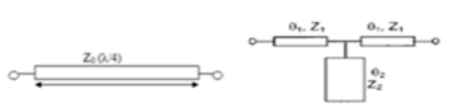

\begin{tabular}{|c|c|c|}
\hline Parameter & Length(mm) & Width(mm) \\
\hline$Z_{1}$ & 5.046 & 0.143 \\
\hline$Z_{2}$ & 4.359 & 5.568 \\
\hline
\end{tabular}

Figure 5. (a) $\lambda / 4$ Transmission lines (b)T-shaped structure of $\lambda / 4$ Transmission lines.

Thus the Proposed branchlinebalun can be realized by the vertical and horizontal branches of T-shaped structure such that the total electrical length will be $\Theta_{\mathrm{T}}=73^{\circ}$ for both the branches.

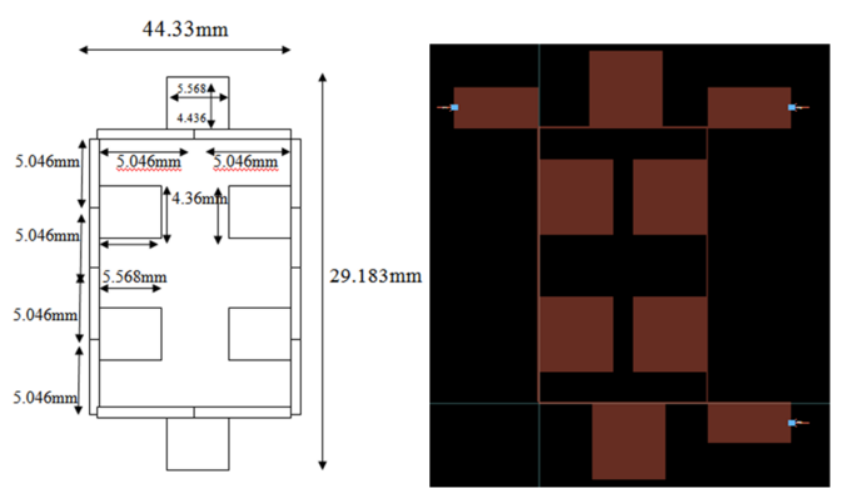

Figure 6. Layout of Proposed T-Shaped balun structure with its dimension.

\section{Results And Discussion}

Thus the Proposed T-shapedbalun is designed and simulated using the ADS software are shown in Fig. 6 with its dimensions. The balun operates at the frequency of $2.4 \mathrm{GHz}$. Thus the structural balun achieves $38 \times 51 \mathrm{~mm}^{2}$ of size while the proposed balun achieves $29 \times 44 \mathrm{~mm}^{2}$ of size. Therefore the balun achieves $35 \%$ size reduction. 


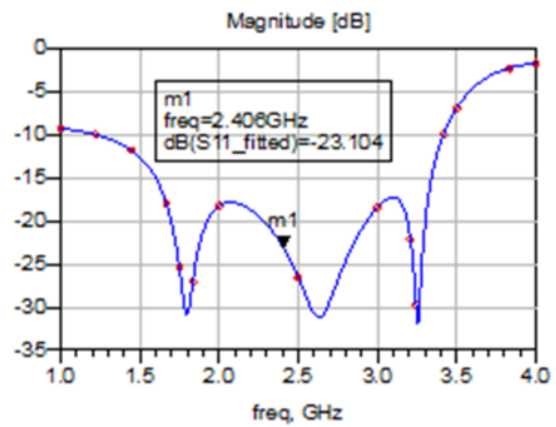

Figure 7. The simulation result of $S_{11}$
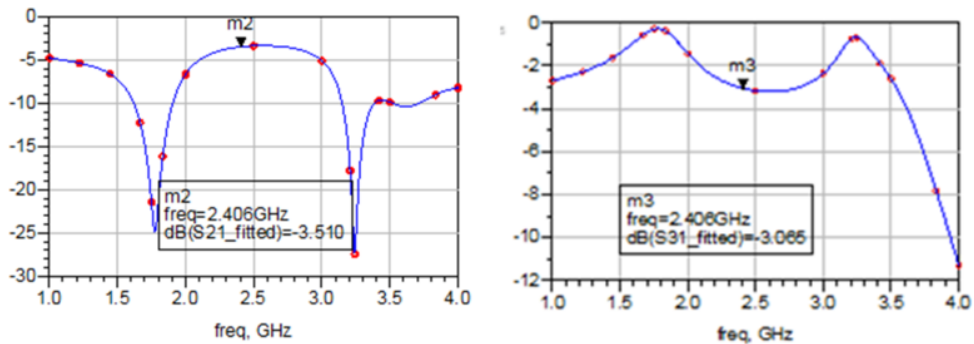

Figure 8. Simulated results of $S_{21}, S_{31}$

The simulated $\mathrm{S}_{21}, \mathrm{~S}_{31}$ are $-3.510 /-3.066$ and simulated $\mathrm{S}_{11}$ are $-23 \mathrm{~dB}$. Therefore the balun obtains $179^{0}$ phase differences between the output $\mathrm{S}_{21}, \mathrm{~S}_{31}$ of the same frequency of $2.4 \mathrm{GHz}$. The bandwidth is about $200 \mathrm{MHz}$ for $\mathrm{S}_{11}$. Also the output of $\mathrm{S}_{21}$ lies at constant $-3 \mathrm{~dB}$ from frequency of 2.2 to $2.9 \mathrm{GHz}$ and the bandwidth of $\mathrm{S}_{21}$ is $700 \mathrm{MHz}$ while the output of $\mathrm{S}_{31}$ remains at constant $-3 \mathrm{~dB}$ from the frequency of 2.3to2.9 $\mathrm{GHz}$ and the obtained bandwidth is $600 \mathrm{MHz}$. The phase imbalance of compact branch line balun is shown in Fig.8. Thus the total phase difference between $\mathrm{S}_{21} \& \mathrm{~S}_{31}$ is $179^{0}$. The proposed balun obtains $35 \%$ of size reduction. Thus the balun achieves better return loss and insertion loss and also results in good amplitude and phase imbalance[11-13].

Thus the performance of the proposed balun parameters are compared with the structural branch line balun is shown in Table3. Thus the proposed design obtain better results and provide good amplitude and phase imbalance and also obtain $179^{\circ}$ phase difference between the two output. Therefore $35 \%$ size reduction is achieved. Thus the performance of the proposed balun parameters are compared with the structural branch line balun.

Table 3. Performance of the proposed balun in comparison with structural branch line balun

\begin{tabular}{|c|c|c|}
\hline Parameters & Structural Balun & Proposed Balun \\
\hline Frequency & \multicolumn{2}{|c|}{$2.4 \mathrm{GHz}$} \\
\hline Size $(\mathrm{mm} 2)$ & $38 \times 51$ & $29 \times 44$ \\
\hline S11(dB) & -31.369 & -23.071 \\
\hline S21,S31 (dB) & $-3.453,-3.340$ & $-3.510,-3.066$ \\
\hline $\begin{array}{c}\text { Phase difference between } \\
\text { S21,S31 (0) }\end{array}$ & 1780 & 1790 \\
\hline
\end{tabular}




\section{Conclusion}

This paper demonstrates the compact branch line balun with reduced size. To reduce the size, a balun is realized using the equivalent T-shape structure. The T-shaped structures presents the closed form of line equations of both quaterwave and halfwave length transmission lines. After the reduction techniques the balun achieves $35 \%$ size reduction. Thus the Branch line balun achieves better return loss and provides good amplitude and phase difference. It provides enhanced bandwidth with low loss and low cost.

\section{Reference}

[1] M. Y. Algumaei, N. A. Shairi, Z. Zakaria and B. H. Ahmad ,A Single Balanced Mixer using Compact Branch Line Balunfor Ultra-wideband Applications. IEEE 2018.

[2] MiZhou,A Novel UniplanarBalunWith Transparent Termination Impedance. IEEE Microwave And Wireless Components Letters, Vol. 29, No. 9, September 2019.

[3] Li Chang and Tzyh-Ghuang Ma, Dual-Mode Branch-Line/Rat-Race Coupler Using Composite Right/Left-Handed Lines.IEEE Microwave And Wireless Components Letters, Vol. 27, No. 5, May 2017.

[4] Chih-Jung Chen, Analytical Derivation of T-Shaped Structures for Synthesis of Quarter-Wavelength Transmission Lines.IEEE Microwave And Wireless Components Letters, Vol. 23, No. 10, October 2013.

[5] He-XiuXu, Guang-Ming Wang, Xin Chen, and Tian-Peng Li, Broadband Balun Using Fully Artificial Fractal-Shaped Composite Right/Left Handed Transmission Line.IEEE Microwave And Wireless Components Letters, Vol. 22, No. 1, January 2012.

[6] Myun-Joo Park and ByungjeLee,Stubbed Branch Line Balun.IEEE Microwave And Wireless Components Letters, Vol. 17, No. 3, March 2007.

[7] J.-L. Li, S.-W. Qu and Q. Xue," Miniaturised branch-line balun with bandwidth enhancement"Electronics Letters 16th August 2007 Vol. 43 No. 17.

[8] Hani Ghali, Tarek A. Moselhy,Miniaturized Fractal Rat-Race, Branch-Line, and Coupled-Line Hybrids. IEEE Transactions On Microwave Theory And Techniques, Vol. 52, No. 11, November 2004.

[9] H.R. Ahn, I.S. Chang, S.W. Yun, Miniaturized 3-dB ring hybrid terminated by arbitrary impedances. IEEE Trans. Microwave Theory Tech. 42(12) (1994) 2216-2221.

[10] Ching-Wen Tang .Miniaturization of Microstrip Branch-Line Coupler With Dual Transmission Lines. IEEE Microwave And Wireless Components Letters, Vol. 18, No. 3, March 2008.

[11] Shry-SannLiao,A Novel Compact-Size Branch-Line Coupler IEEE MICROWAVE And Wireless Components Letters. Vol. 15, No. 9, September 2005.

[12] B.Pavithra, S. Maheswari,Design of Compact 180 degree Hybrid Coupler Using T-Shaped Structure.Advances in Engineering Research(AER), Volume No. 142, Pg. 248-251 -February 2018.

[13] Shirley Helen Judith ,S. Maheswari .Miniaturization of microstripBranchline Coupler for Wireless Application with branched Transmission Lines . 2018 3rd International Conference on Communication and Electronics system, 15,16 October 2018. 